\title{
METALLIC COATING DURABILITY IN SOIL
}

\author{
Zdenek BARTAK
}

\section{SVUOM Ltd., Prague, Czech Republic, EU, bartak@svuom.cz}

https://doi.org/10.37904/metal.2019.906

\section{Abstract}

Geo-components are manufactured from steel, galvanized steel and polymers commonly take the form of reinforcing meshes, straps or strips for high quality erosion and sediment control systems. Prediction of durability of zinc/zinc alloyed coatings can be done on the basis of knowledge of their thickness and zinc/zinc alloyed corrosion rate in soil. Required durability of these systems varies from 20 to 120 years depending on soil corrosivity. The paper gives some data for short exposure of zinc/zinc alloyed coatings in soil. The performed tests show that the corrosion attack of zinc coating in soil is very non uniform and locally may be totally corroded after few years. In such case the service-life of geosystems may be significantly lower that required according to standard and producers specification. Performed tests show the additional protection by PVC coating may be damaged due to installation of geosystems and corrosion of wires may started immediately.

Keywords: Geosystem durability, zinc alloyed coating, corrosion in soil

\section{INTRODUCTION}

The geosystems for civil engineering, mainly the highway represents very important materials for soil reinforcement. Engineered geo-components come in a wide range of shapes, sizes, materials, colours and configurations, all of which provide a specific function within an individual geosystem. Many geo-components are manufactured from steel, galvanized steel and polymers commonly take the form of reinforcing meshes, straps or strips for high quality erosion and sediment control systems - Figure 1.
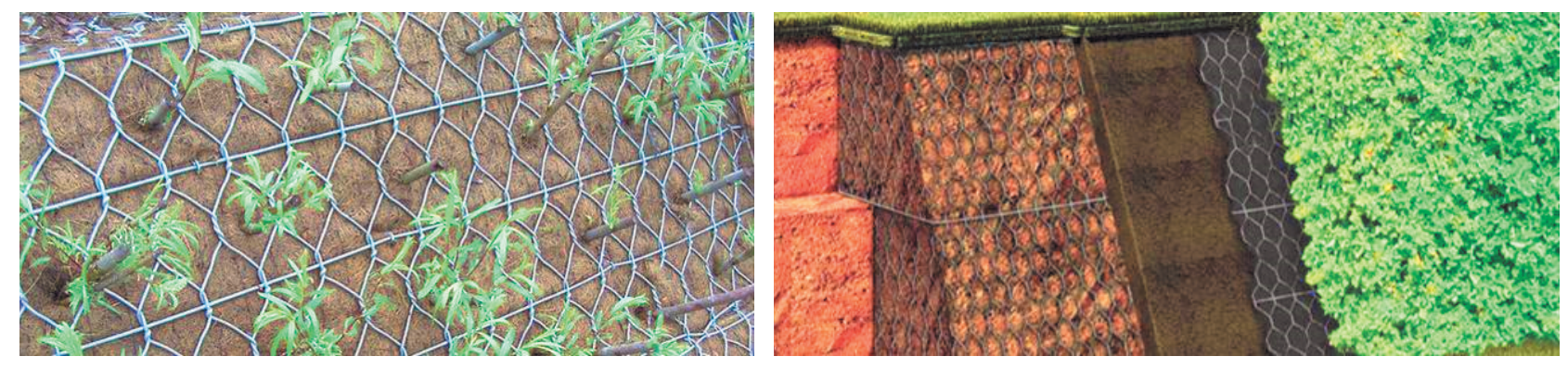

Figure 1 Example of geosystems

Geosystem meets the strict requirements regarding durability. At any site where geosystems may be built, portions of the structure will be exposed to soil, air, water (humidity, precipitation, runoff, groundwater), and sunlight. The types of mesh used, must be of a non-ravelling type such as welded wire mesh or hexagonal woven wire mesh and provided with corrosion protection to suit the required exposure conditions. The PVC coating with nominal thickness $0.5 \mathrm{~mm}$ will give a life expectancy for the structure of up to 120 years providing that the PVC coating is not subjected to mechanical or chemical damage - Table 1. To account for environmental conditions the appropriate soils with $\mathrm{pH}$ values shall be in range 4 - 9 .

The steel wire and mesh are manufactured and coated in accordance with EN 10223-3 Steel wire and wire products for fences - Part 3: Hexagonal steel netting for engineering purposes and EN10244-2 Steel wire and wire products - Non-ferrous metallic coatings on steel wire - Part 2: Zinc or zinc alloy coatings respectively. 
The zinc and/or zinc alloyed coating shall conform to class A. For wire with diameter $2.20 \mathrm{~mm}$ it is minimally 230 g.m ${ }^{-2}$.

Table 1 Anticipated design life (years)

\begin{tabular}{|c|c|c|c|c|}
\hline Soil corrosivity & Very low & Low & Medium & High \\
\hline Zn & 60 & 20 & not recommended & not recommended \\
\hline Zn15Al & 120 & 60 & not recommended & not recommended \\
\hline Zn15Al +PVC & $>120$ & $>120$ & 120 & 60 \\
\hline
\end{tabular}

Prediction of durability of zinc coating can be done on the basis of knowledge of their thickness and zinc corrosion rate in given environment. Standard EN ISO 14713-1 Zinc coatings - Guidelines and recommendations for the protection against corrosion of iron and steel in structures - Part 1: General principles of design and corrosion resistance in clause 7.2. Exposure in soil gives very general data. The corrosion, particle abrasion, impacts from falling rocks, and other impacts will likely affect wire coatings, wear away or break the wires. The oldest installed geosystems exhibit over 40 years.

\section{EXPERIMENTAL}

\subsection{Materials}

The sample of mesh was buried to simulate the procedure of installation of geosystem - the arches mesh panel should be unfolded; the shipping folds flattened out, and pulled tight to minimize future creepage. The granular backfill were installed in maximum lifts of approximately $300 \mathrm{~mm}$. The valuation had been done on part of hexagonal woven wire mesh, ca $300 \times 600 \mathrm{~mm}$, made from galvanized and PVC coated wire mesh $(8 \times 10$ mesh type), wire diameter $2.20 \mathrm{~mm}$ - Figure 2 .
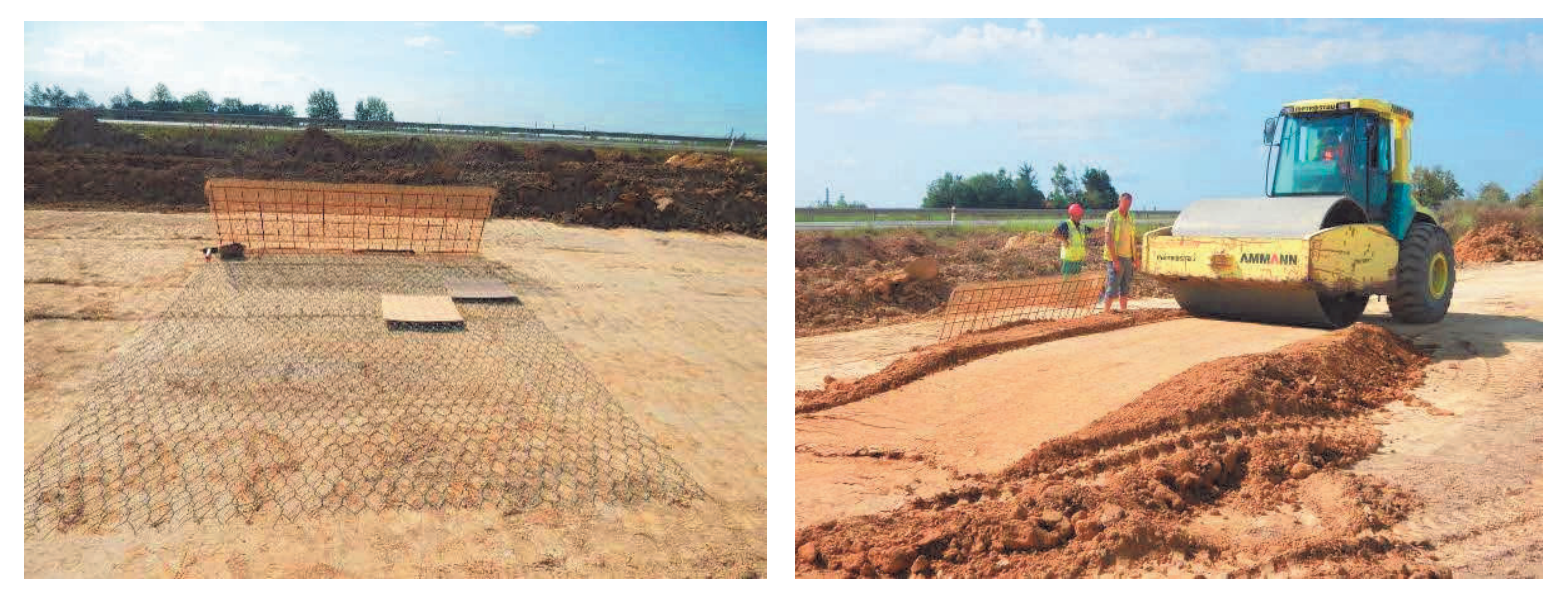

Figure 2 Sample of mesh for tests - simulation of installation

Polymer coating is cracked in twisted areas and zinc coating thickness distribution is not uniform around the wire diameter - Figures 3 and $\mathbf{4}$. The metallic coating also shows a lot of cracks in layer. Wire coatings and the underlying wire are abraded when soil particles impinge upon and grind them during installation. After this simulation the number of damages - cracks in polymer coating - was estimated as $12 \%$ defects on twisted units of grid - Figure 5. Visual evaluation was done by 3D digital microscope Keyence VHX-5000, Japan.

The thickness of metallic coating was measured on samples withdrawn from mesh by gravimetric method according to EN ISO 1460 Metallic coatings - Hot dip galvanized coatings on ferrous materials - Gravimetric determination of the mass per unit area and metallographic method according to EN ISO 1463 Metallic and 
oxide coatings - Measurement of coating thickness - Microscopical method. The value was 243 g.m-2, respectively $34 \mu \mathrm{m}$.
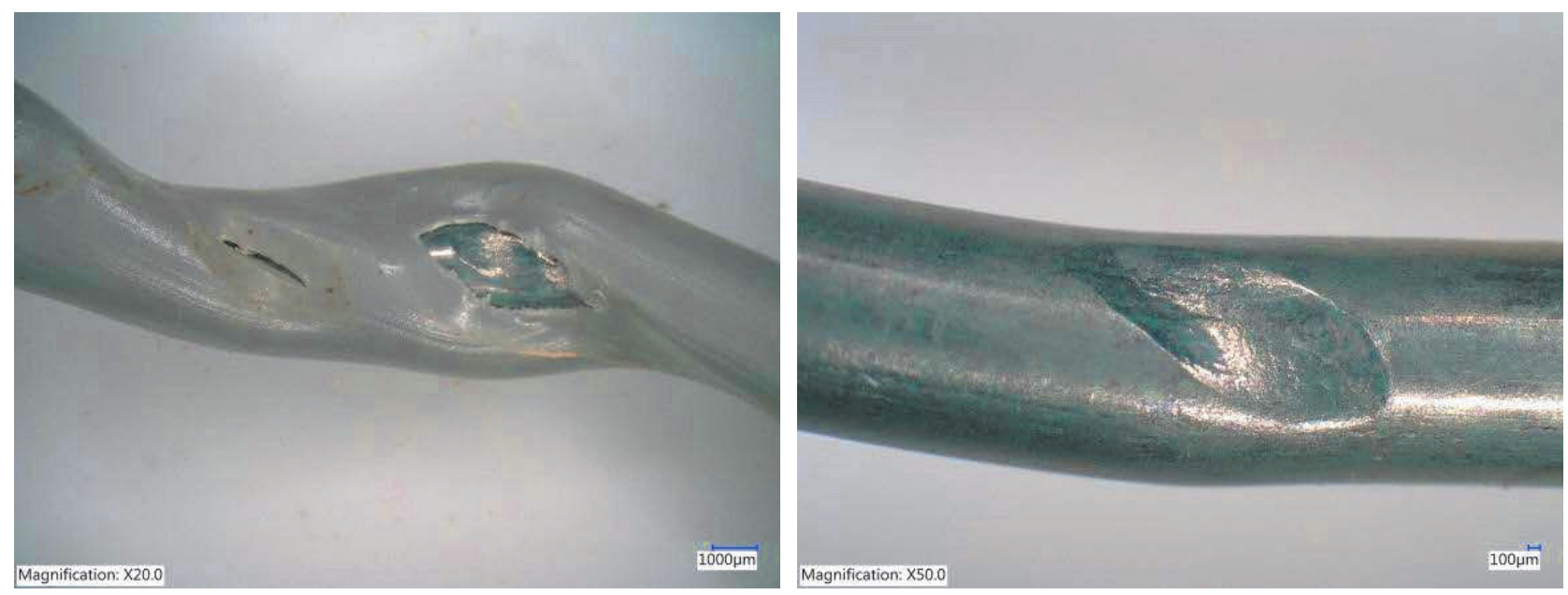

Figure 3 Damage of polymer and metallic coatings due to production
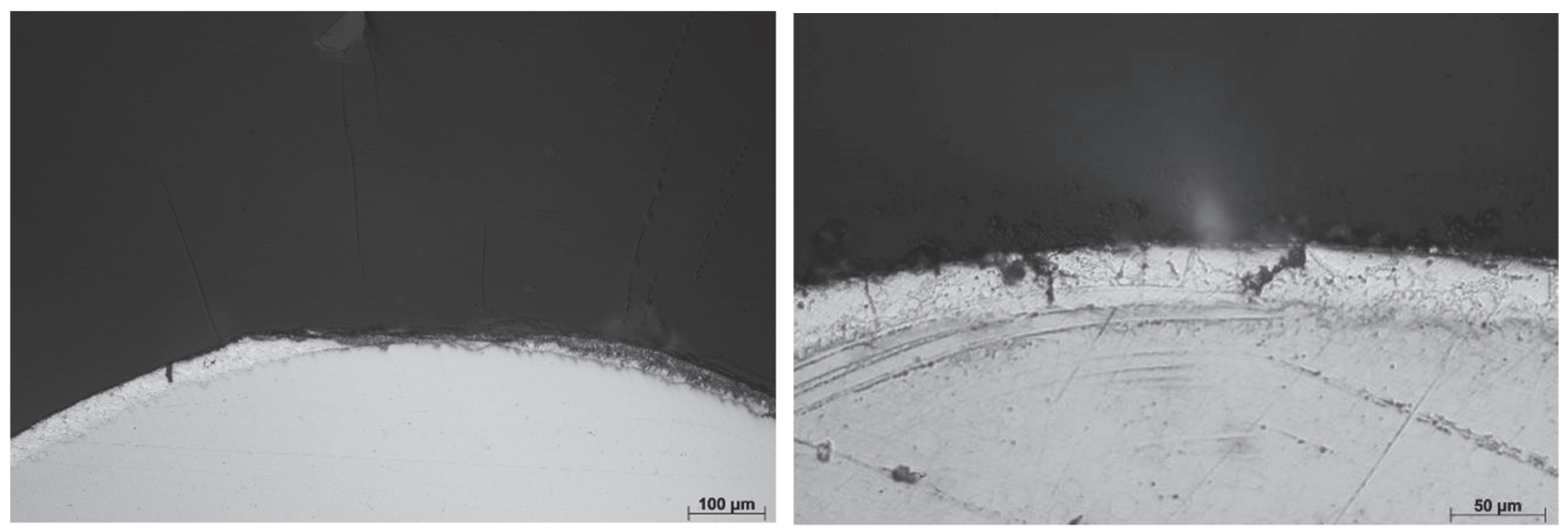

Figure 4 Cross section of non-exposed metallic coatings
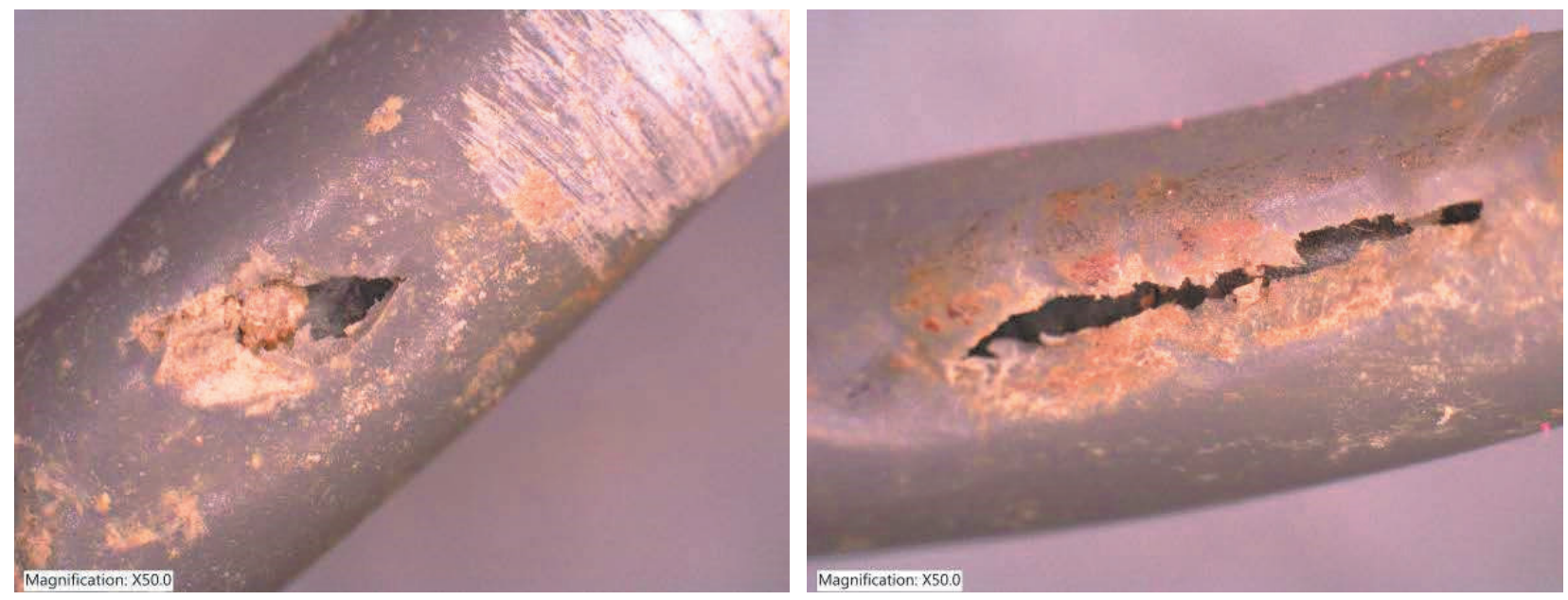

Figure 5 Example of damage of polymer coating due to installation of mesh in soil 


\subsection{Accelerated tests}

According to EN 10233 no sign of dark brown can be seen after 6000 hrs of exposure in salt spray test according to EN ISO 9227 Corrosion tests in artificial atmospheres - Salt spray tests. But this test does not give any information for corrosion protection durability. Corrosion loss of zinc coating on wires after 500 hrs exposure was 15 to $25 \mu \mathrm{m}$ and corrosion loss of zinc alloyed coating was lower for 50 to $70 \%$. The first rust stains occurred on wires with $35 \mu \mathrm{m}$ zinc alloyed coating after ca $4500 \mathrm{hrs}$.

Mesh samples were exposed into QUV/spray cyclic test in chamber Q-Lab, USA, according to EN ISO 164743 Paints and varnishes - Methods of exposure to laboratory light sources - Part 3: Fluorescent UV lamps. The exposure period was $1400 \mathrm{hrs}$. The polymer coating was intensively degraded in areas of crack but the zinc coating only slightly darker - Figure 6.
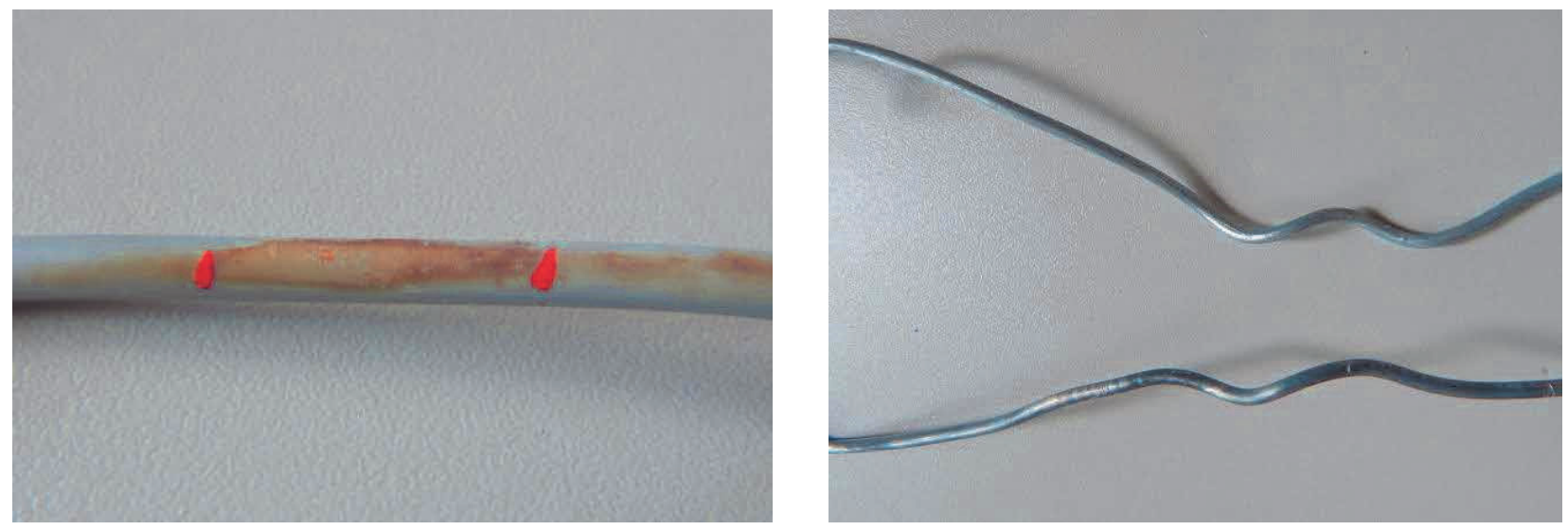

Figure 6 Damage of polymer and metallic coatings after QUV/spray test

Mesh samples were exposed into condensation test according to EN ISO 6270-2 Paints and varnishes Determination of resistance to humidity - Part 2: Procedure for exposing test specimens in condensation-water atmospheres. The exposure period was $3000 \mathrm{hrs}$. The zinc coating intensively corroded in areas of damaged polymer coating - Figure 7. Even the substrate steel corrosion spots occurred.
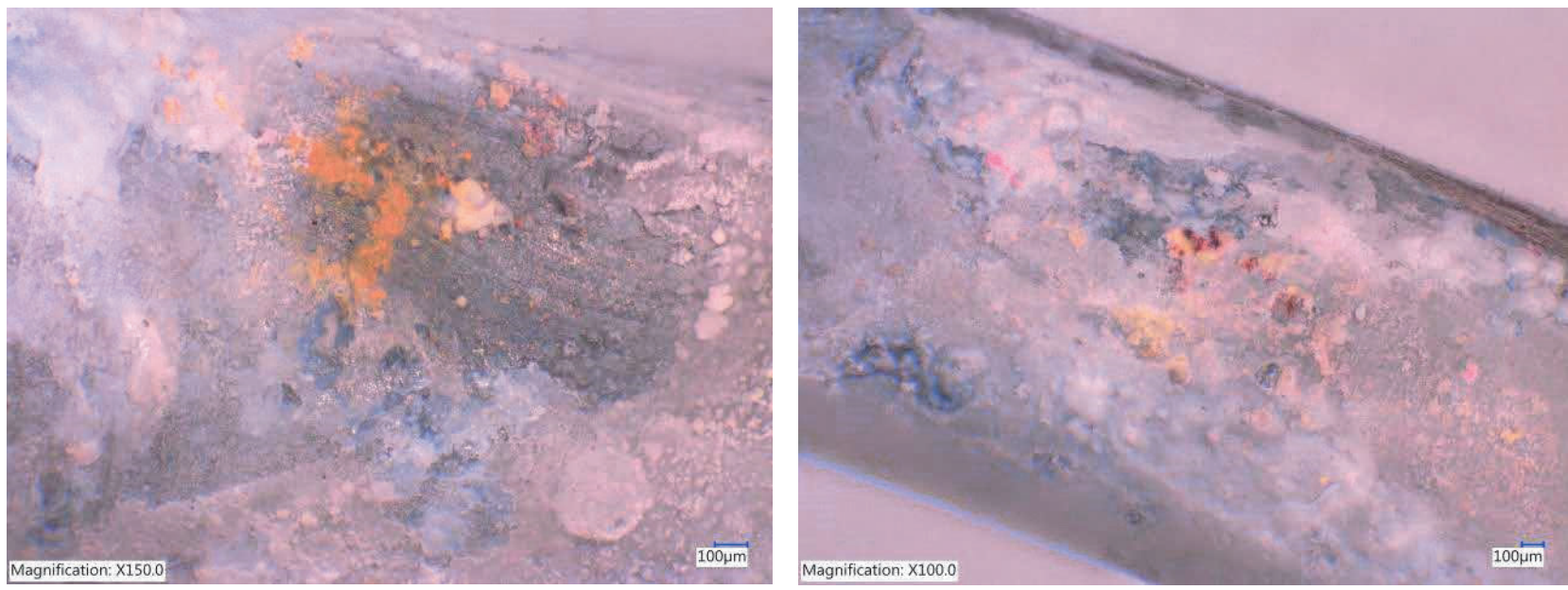

Figure 7 Damage of metallic coatings after condensation test

\subsection{Field tests}

The samples of mesh with various surface coating were exposed at all 3 atmospheric test sites for 4 years. There were not evident any degradation of metallic and polymer coatings. 
The wires with Zn15Al coating were exposed in soil (test site SVUOM in Horomerice) after 1 year. Corrosion loss of metallic coating was ca $35 \mu \mathrm{m}$ according to gravimetric measurement but the corrosion attack of coating was very non uniform according to cross-section image - Figure $\mathbf{8}$. In pits the zinc alloyed coating is practically totally corroded.
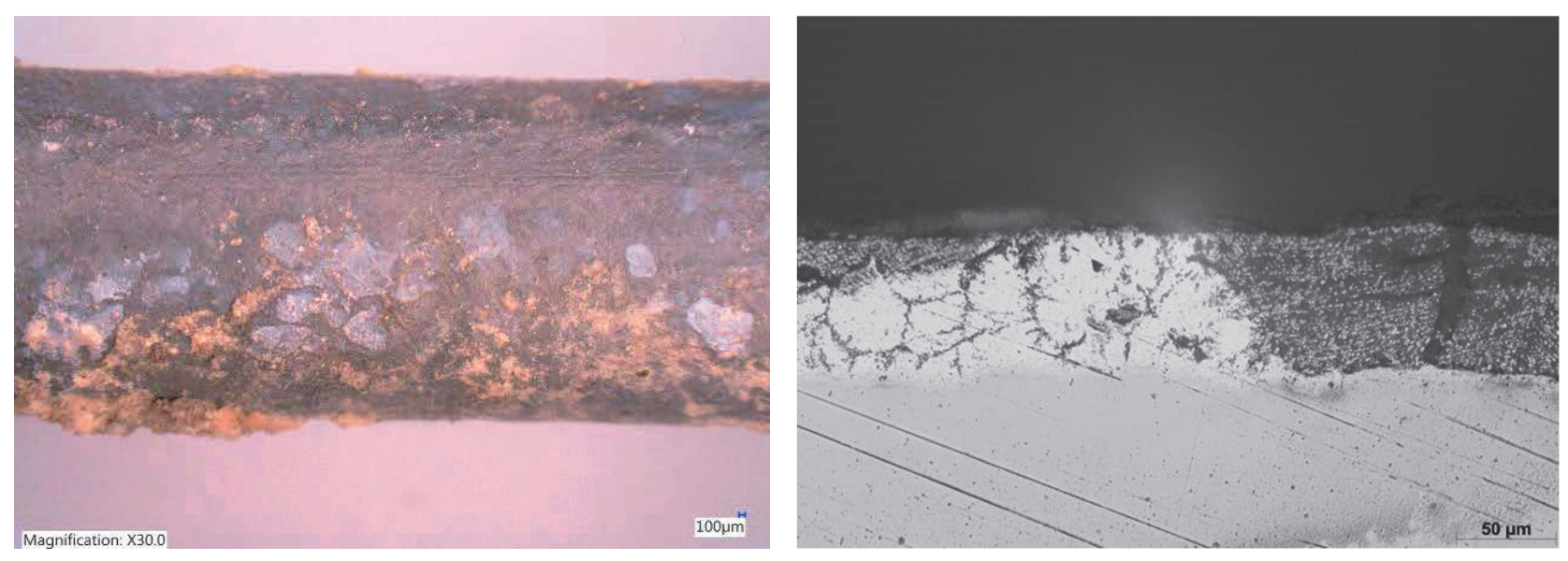

Figure 8 Corrosion of zinc alloyed coating after 1 year exposure in soil

\section{RESULTS AND DISCUSION}

Corrosion of metals in soil is electrochemical process its rate depends on soil corrosivity, i.e. minerals content, their types and on content of organic compounds, carbon dioxide, water and oxygen in soil (aerobic and anaerobic corrosion). General information about corrosion likelihood in soil can be found in standard EN 12501-1 Protection of metallic materials against corrosion - Corrosion likelihood in soil - Part 1: General, but without corrosion rate values. HDG, AZ and ZMA coatings showed higher corrosion rate in badly aerated soils with high moisture.

Prediction model calculates durability as period till time to total corrosion of zinc coating and $25 \%$ loss of original thickness of wire diameter - Table 2. Corrosion tests in soil show that corrosion rate of carbon steel and zinc is higher in initiation period ca 2 - 4 years and subsequently the rate of corrosion procedure becomes slower [1]. The first year corrosion rate in soil with low corrosivity in the CR was estimated for zinc as $8 \mu \mathrm{m}$ and for carbon steel $30 \mu \mathrm{m}$ [2]. According these values the steady corrosion rate shall be $2 \mu \mathrm{m} \cdot \mathrm{a}^{-1}$ for zinc and $7 \mu \mathrm{m} . \mathrm{a}^{-1}$ for carbon steel. After 3 years of exposure in soil the zinc coating shows pits with depth of $25 \mu \mathrm{m}$ to $35 \mu \mathrm{m}$ measured by 3D digital microscope Keyence VHX-5000. The Zn15Al coating gives approximately 1.5 to 4 times the durability of a pure zinc coating.

Table 2 Prediction model of durability of galvanised steel

\begin{tabular}{|c|c|c|c|}
\hline \multirow{2}{*}{ Material } & \multirow{2}{*}{ Model } & \multicolumn{2}{|c|}{ durability (years) } \\
\cline { 3 - 4 } & & low corrosive soil & high corrosive soil \\
\hline zinc coating & $T_{Z n}=D_{Z n} / r_{c o r r z n}$ & 10 & $<1$ \\
\hline substrate steel & $T_{S t}=1 / 4 D_{S t} / r_{c o r r s t}$ & 120 & 5 \\
\hline total durability & $T=T_{Z n}+T_{S t}$ & 130 & 6 \\
\hline
\end{tabular}

where $r_{c o r r}$ is average steady corrosion rate of metal (zinc, steel) in given environment $\left(\mu \mathrm{m} \cdot \mathrm{a}^{-1}\right)$,

$D_{z n}$ is coating thickness $(\mu \mathrm{m})$,

$D_{s t}$ is wire diameter $(\mu \mathrm{m})$. 
When investigating the performance and durability of engineering materials, some sort of failure criterion is needed. A long-term field study of corrosion and other damaging effects on wires of gabion mesh was performed at 14 sites in California [3]. Two styles of mesh were studied: twisted hexagonal and welded squaregrid. The wires had corrosion protection coatings of either zinc, zinc-and-polyvinyl chloride (PVC-coated), or aluminum including the same type as tested in the CR. The galvanized wires with damaged PVC coated were totally broken after 13 wet seasons - Figure 9 .
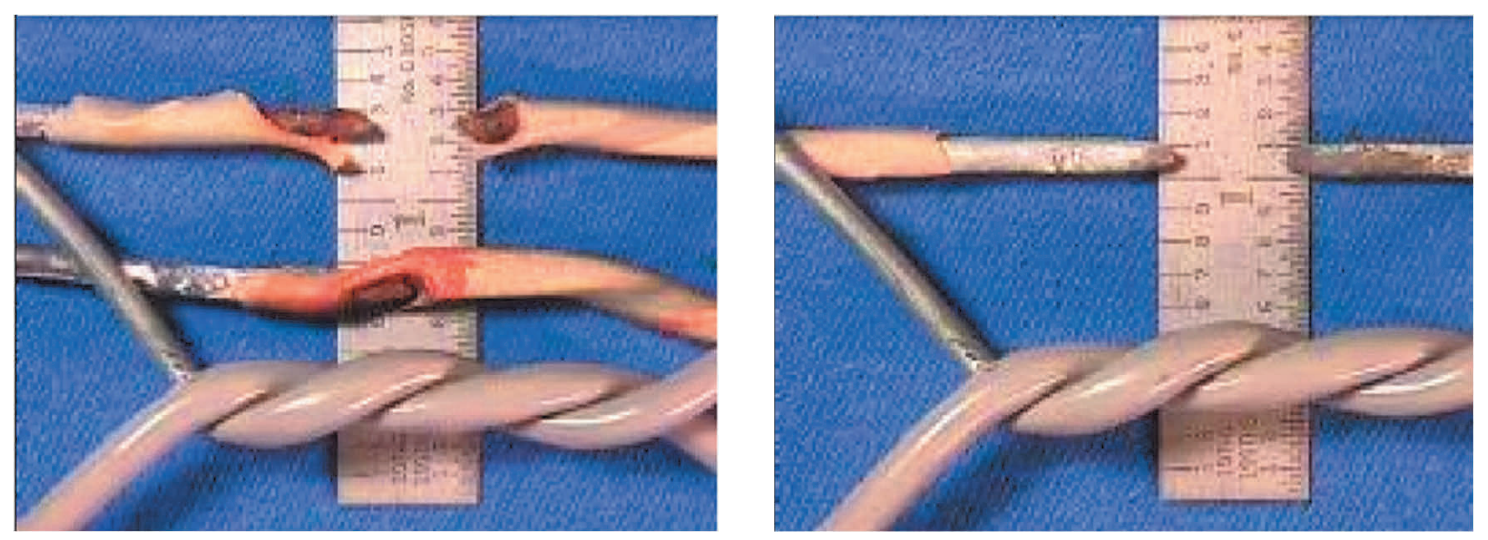

Figure 9 Broken coated wires after exposure in soil

\section{CONCLUSION}

Corrosion and abrasion are natural effects that decreased the service-life of geosystems. Field tests show that PVC coating degraded after about 3 to 5 years of exposure to sunlight, and after about 7 years the surfaces of sun-exposed PVC coating developed cracks. Where meshes were submerged in either mud or water, PVC hardened and may cracked, too. In these areas corrosion of metallic coating starts. But in case that PVC coating is mechanically damaged during geosystems' installation the corrosion of metallic coating starts immediately and spreads beneath PVC coating. Depending on corrosivity of soil the durability of geosystem may be 120 years according to standard requirement or only 6 years. The performed tests show that the corrosion attack of zinc coating in soil is very non uniform and locally may be totally corroded after few years. In such case the service-life of geosystems may be significantly lower that required according to standard and producers specification.

\section{ACKNOWLEDGEMENTS}

The study was performed and paper was written with support of project MPO - IP 8/2018.

\section{REFERENCES}

[1] Service Life of Galvanized Steel Articles in Soil Applications, www.aga.org.

[2] KREISLOVA, K., BARTAK, Z., FIALOVA, P., MAJTAS, D., Corrosion behaviour of hot dip zinc coatings in soil, In 23rd Conference of galvanizing, Dolní Morava, AČSZ, 2017, pp. 68 - 78

[3] RACIN, J. A., HOOVER, T.P., GABION MESH CORROSION Field Study of Test Panels and Full-scale Facilities, Final Report No. FHWA-CA-TL-99-23, Study No. F93TL02 S, November 2001, USA. 